\title{
O TRATO COM O CONHECIMENTO DA GINÁSTICA EM CLASSES MULTISSERIADAS: APONTAMENTOS DA PEDAGOGIA HISTÓRICO- CRÍTICA E DA METODOLOGIA DO ENSINO DA EDUCAÇÃO FÍSICA CRÍTICO-SUPERADORA PARA O CURRÍCULO DAS ESCOLAS PÚBLICAS
}

\author{
ADDRESSING GYMNASTICS KNOWLEDGE IN MULTI-GRADE \\ CLASSES: NOTES FROM HISTORICAL-CRITICAL PEDAGOGY AND \\ METHODOLOGY FOR TEACHING CRITICAL-OVERCOMING PHYSICAL \\ EDUCATION FOR PUBLIC SCHOOL CURRICULUM
}

EL TRATO CON EL CONOCIMIENTO DE LA GIMNASIA EN CLASES

MULTISERIADAS: APUNTES DE LA PEDAGOGÍA HISTÓRICO-CRÍTICA Y DE LA METODOLOGÍA DE LA ENSEÑANZA DE LA EDUCACIÓN FÍSICA CRÍTICO-SUPERADORA PARA EL CURRÍCULO DE LAS ESCUELAS PÚBLICAS

\section{Celi Nelza Zulke Taffarel*, Cláudio dos Santos Costa**, Jaildo Calda dos Santos Vilas Bôas Júnior*}

Palavras chave: Educação. Educação Física. Ginástica. Zona rural.

Keywords: Education. Physical Education. Gymnastics. Rural areas.

Palabras clave: Educación. Educación Física. Gimnasia. Medio rural.
Resumo: $O$ texto tem como objetivo identificar as contribuições teóricometodológicas da Pedagogia Histórico-Crítica (PHC) e da Abordagem CríticoSuperadora (ACS) para o trato com o conhecimento da Ginástica, em classes multisseriadas, nas escolas públicas do campo. Partindo da realidade concreta das escolas que estão sendo fechadas em decorrência da aplicação da política baseada em ajustes estruturais e da negação sistemática do acesso ao conhecimento clássico, na disciplina Educação Física, para os estudantes do campo, estamos apresentando elementos teórico-metodológicos advindos da PHC e da ACS para subsidiar o trabalho educativo e suas possibilidades superadoras no trato com o conhecimento da Ginástica.

Abstract: The text identifies the theoretical-methodological contributions of Historical-Critical Pedagogy (HCP) and the Methodology for Teaching CriticalOvercoming Physical Education to address gymnastics knowledge in multi-grade classes in rural public schools. Based on the concrete reality of schools that are being closed as a result of structural adjustment policies, we present theoretical and methodological elements derived from HCP and the Methodology for Teaching Critical-Overcoming Physical Education to inform educational work and its overcoming possibilities when addressing gymnastics knowledge.

Resumen: El texto tiene como objetivo identificar las contribuciones teóricas y metodológicas de la pedagogía histórico-crítica (PHC) y de la Aproximación Crítico-Superadora (ACS) para tratar el conocimiento de la Gimnasia, en clases multiseriadas, en las escuelas públicas del campo. Partiendo de la realidad concreta de las escuelas que se están cerrando debido a la política basada en ajustes estructurales y de la negación sistemática del acceso al conocimiento clásico, en la disciplina Educación Física, para los estudiantes del campo, estamos presentando elementos teórico-metodológicos provenientes de la PHC y de la ACS para subsidiar el trabajo educativo y sus posibilidades superadoras en el trato con el conocimiento de la Gimnasia.
*Universidade Federal da Bahia Salvador, BA, Brasil. E-mail: taffarel@ufba.br; vilasboasjr1@gmail.com

**Universidade Católica da Bahia Salvador, BA, Brasil. Universidade Federal da Bahia, Salvador, BA Brasil.

E-mail:

claudio.costa_91@hotmail.com

Recebido em: 30-10-2018 Aprovado em: $14-04-2020$ Publicado em: 25-05-2020 


\section{INTRODUÇÃO}

As expressões da aplicação das políticas pró-imperialistas, fundomonetaristas de ajuste fiscal (MONTORO, 2014) no Brasil, podem ser identificadas no fechamento de escolas, no campo e na cidade, bem como e na precariedade da infraestrutura das que permanecem abertas. Esse processo, como denunciou o Movimento dos Trabalhadores Rurais Sem Terra (MST) na campanha "Fechar escola é crime", fechou mais de 24 mil escolas do campo entre 2003 e 2011. O pesquisador Paulo Alentejano e a pesquisadora Tássia Cordeiro, da Universidade Estadual do Rio de Janeiro (UERJ), constataram, com base no Censo Escolar 2019, divulgado pelo Ministério da Educação, em 30 de dezembro, que no último ano o campo teve queda de 145.233 matrículas na soma de todas as modalidades de ensino - foram 5.195.387 registrados em 2018, contra 5.050.154 em 2019. Estes indicadores corroboram com dados sobre fechamento de escolas do campo levantados por Alentejolo e Cordeiro ${ }^{1}$. Foram fechadas quase 80 mil escolas no campo brasileiro entre 1997 e 2018, somando quase 4 mil escolas fechadas por ano². Os dados do II PNERA - Pesquisa Nacional sobre a Educação na Reforma Agrária $^{3}$-, já apontavam que ao longo da última década o número de escolas do campo brasileiras fechadas aumentou. As escolas foram reduzidas em $31,46 \%$, ou seja, 32.512 unidades foram fechadas. Ora, não se enfrenta os problemas da educação do campo fechando escolas.

Além disso, especialmente na educação do campo, após o afastamento da presidenta Dilma Rousseff, democraticamente eleita, em 2014, e afastada através de um golpe imperialista, parlamentar, com apoio de parte do empresariado, dos militares, da mídia e da própria classe média, a Secretaria de Educação Continuada, Alfabetização, Diversidade e Inclusão (SECADI) sofreu um processo de desmonte com a paralisação dos setores de orçamento e planejamento ${ }^{4}$. Isso acarretou no sucateamento de projetos importantes, em decorrência de cortes orçamentários como, por exemplo, na terceira e quarta edição do Programa Escola da Terra ${ }^{5}$, que visava garantir a formação continuada de docentes, com consistente base teórica, para melhoria da qualidade do ensino nas escolas do campo. Some-se a isso, a Lei 13.365/2016 que revoga a destinação do fundo social dos royalties do petróleo para educação e saúde; a Emenda Constitucional - EC 95/16 que estabelece um teto para gastos públicos, implicando em não investimentos nos próximos anos, e o Projeto de Lei Complementar $n^{\circ} 257 / 2016$ que ameaça o piso do magistério e a política salarial dos servidores públicos; há, também, nesse momento, a tramitação no congresso da PEC 15/15 que torna o Fundo de Desenvolvimento da Educação Básica e Valorização dos Profissionais da Educação (FUNDEB) permanente que, se não for aprovada,

\footnotetext{
1 Disponível em: https://www.brasildefato.com.br/2019/11/29/artigo-or-80-mil-escolas-no-campo-brasileiro-foramfechadas-em-21-anos. Acesso em: 05 maio 2020.

2 Dados do I Encontro de Profissionais da Educação de Classes Multisseriadas da Bahia confirmam estes dados. Disponível em: https://faced.ufba.br/sites/faced.ufba.br/files/i encontro profissionais classes multiseriadas bahia. pdf. Acesso em: 27 mar. 2020.

3 BRASIL. II PNERA - Relatório da II Pesquisa nacional sobre educação na reforma Agrária. Brasília: MDA. 2015.

4 Sobre a Extinção da SECADI: Um golpe fatal nas conquistas da Educação do Campo. Ver TAFFAREL; Celi; CARVALHO, Marize. Disponível em: https://revistas.uece.br/index.php/CadernosdoGPOSSHE/article/view/1523 .

5 O Programa Escola da Terra é ação do Eixo n 1 do Programa Nacional de Educação do Campo (PRONACAMPO), Programa lançado pelo Governo Federal em 20 de março de 2012, Portaria $n^{\circ} 86$ de 02 de fevereiro de 2013, que define ações específicas de apoio quanto à efetivação do direito à educação dos povos do campo e quilombola, considerando as reivindicações históricas oriundas dessas populações. No estado da Bahia foram atendidos, nas duas edições do curso, mais de 1.500 professores de uma demanda de, aproximadamente, 13 mil professores.
} 
acarretará sérios retrocessos para educação básica do país; dentre outras medidas que já representam ameaças concretas a classe trabalhadora. Esse desmonte e ataque aos direitos demonstram uma ofensiva contra o direito à educação (de qualidade), previsto na Constituição Federal de 1988 (Art. 6). A consequência social é que as crianças e jovens do campo cada vez mais estão enfrentando dificuldades para ter o direito de acesso à educação pública de qualidade garantido.

Nos posicionamos, portanto, em meio a embates de projetos/lógicas de produção e reprodução da vida, que no meio de fortes contradições e conflitos se desenha hoje no campo. Defendemos, assim como Caldart ${ }^{6}(2020)$, o reposicionamento das finalidades da educação, a reconstituição e o redesenho da função social das escolas do campo. Nos termos da autora:

\begin{abstract}
Há uma escolha radical a fazer. Colocar a escola a serviço das demandas de produção e reprodução do capital na agricultura que, mesmo quando o agronegócio tenta se pintar de "verde" (o do "negócio dos orgânicos"), sempre apequenam o horizonte formativo e não impedem o fechamento de escolas no campo. Ou inserir a escola na construção da vida humana e social das comunidades camponesas, fortalecida na relação entre agroecologia e luta pela transformação do sistema social, construção que exige/possibilita trabalhar pelo desenvolvimento multilateral do ser humano. (CALDART, 2020, p. 9)
\end{abstract}

Ao sistematizar as contribuições da Pedagogia Histórico-Crítica e da Abordagem Crítico-Superadora do ensino da Educação Física para propor o trato com o conhecimento específico da Ginástica em classes multisseriadas (em contexto de fechamento de escolas e desmonte da educação pública), o fazemos considerando que esse tipo de sala é comum na Educação do Campo das Escolas Públicas da Bahia.

Estamos considerando, para tanto, as contribuições de Marsiglia e Martins (2014, p. 182-184) que versam sobre o planejamento escolar, considerando a tríade conteúdo-forma e destinatário no planejamento tanto vertical quanto o horizontal. Nesse sentido, o primeiro corresponde à identificação das categorias (conceitos mais gerais) que o estudante precisa se apropriar, relativo ao objeto de ensino (no nosso caso, a cultura corporal e, especificamente, a Ginástica), tendo em vista o desenvolvimento das funções psíquicas a médio e longo prazo. Isto significa ordenar os conceitos que serão trabalhados, transmitidos, durante uma aula, uma unidade, um semestre, um ano letivo, um ciclo de escolarização. As categorias centrais do plano vertical são denominadas de núcleos conceituais. Os referidos núcleos são referências centrais para todo conteúdo do plano horizontal e aparecem, ainda que implicitamente, constantemente no processo do trabalho educativo, em todas as aulas, ou sessões. O plano horizontal compreende à identificação dos conteúdos que especificam, particularizam e aprofundam as categorias centrais que constam no plano vertical, ampliando assim a visão de totalidade, radicalidade e rigorosidade no trabalho formativo, que vai sendo ampliado e aprofundado de ciclo para ciclo de escolarização. Em linhas gerais, em nosso caso, os núcleos conceituais do planejamento seriam as bases e fundamentos histórico, políticos, filosóficos e técnicos da ginástica.

6 CALDART; Roseli Salete. Função social da escola do campo e desafios educacionais do nosso tempo. [Texto preparado para Aula Inaugural do semestre do curso de Licenciatura em Educação do Campo, da Universidade Federal do Rio Grande do Sul, Campus Litoral, realizada em 9 de março 2020]. 
Ao propormos tal abordagem para o planejamento da ginástica no currículo escolar, o fazemos levando em conta, portanto, a função social da escola que, segundo Saviani (2013, p. 17), é transmitir os conhecimentos clássicos para novas gerações e elevar a capacidade teórica dos estudantes. Segundo Caldart (2020), é elevar a capacidade de interpretar seu meio, seu território, seu espaço, tempo e história e tomar posição na construção da cultura e na transformação da realidade concreta do campo. (CALDART, 2020, p.1)

Assim, nos perguntamos, para tanto: quais as contribuições teóricas da Pedagogia Histórico-Crítica (PHC) e da Abordagem Crítico-Superadora (ACS) do Ensino da Educação Física para o currículo escolar, em especial no trato com o conteúdo da Ginástica em escolas do campo multisseriadas?

Objetiva-se, portanto, apontar as contribuições da PHC e da ACS no ensino da Educação Física, para o currículo e para o trato do conteúdo da Ginástica em escolas do campo multisseriadas.

O tipo de pesquisa desenvolvido foi a análise de referências bibliográficas clássicas da PHC e análise documental indireta a partir do levantamento dos artigos, teses e dissertações que tratam do desenvolvimento humano e do ensino da Ginástica na Educação Física Escolar ancorados na PHC e na ACS do ensino da Educação Física. Para apontar contribuições da PHC e da ACS, analisamos 6 obras que versam sobre a referida temática, a saber: 1 - Metodologia do ensino da Educação Física (SOARES et al., 2012); 2 - Escola e Democracia (SAVIANI, 2012); 3 - Pedagogia Histórico-Crítica: primeiras aproximações (SAVIANI, 2013); 4 - O desenvolvimento do psiquismo e a educação escolar: contribuição à luz da psicologia histórico-cultural e da pedagogia histórico crítica (MARTINS, 2013); 5 - As perspectivas construtivistas e histórico-crítica sobre o desenvolvimento da escrita (MARTINS; MARSIGLIA, 2015); 6 - Periodização histórico-cultural do desenvolvimento psíquico: do nascimento a velhice (MARTINS; ABRANTES; $\mathrm{FACCl}, 2016)$.

Levamos em consideração, ainda, a tese defendida por Teixeira (2018) que teve como objeto Educação Física na Pré-escola, e delimitou seu conteúdo a responder a pergunta síntese sobre "quais orientações específicas devem nortear o ensino da Educação Física Escolar na Pré-escola a partir das contribuições da Abordagem Crítico-Superadora? Teixeira (2018) apresentou parâmetros teóricometodológicos de uma Educação Física Crítico-Superadora para o primeiro ciclo de escolarização, no intuito de contribuir para superar a negação do conhecimento referente das atividades da Cultura Corporal na rede pública de ensino. Como contribuição teórica inédita, apresenta proposta de organização do trato pedagógico do conhecimento da Ginástica no primeiro ciclo de escolarização, a partir das contribuições da periodização do desenvolvimento psíquico, referendada na teoria Histórico-Cultural, e dos conhecimentos da motricidade infantil. Teixeira (2018) sustentou a tese de que:

[...] o ensino sistematizado dos conteúdos da Cultura Corporal deve fazer parte do núcleo central do currículo da Educação Infantil - desde as creches - primeira etapa do processo da educação escolarizada, uma vez que o ser social, principalmente nesta fase da vida, acessa a humanidade 
- pelo domínio dos signos culturalmente desenvolvidos por meio da sua organização corporal, condição que contribui para o desenvolvimento infantil nas suas múltiplas dimensões, e que o ensino orientado pela abordagem Crítico-Superadora das atividades da Cultura Corporal potencializa o desenvolvimento do psiquismo infantil. (TEIXEIRA, 2018, p. 8)

Nos valemos, também, das contribuições de Almeida (2005) que tratou da Ginástica na escola e na formação de professores, tecendo críticas aos conteúdos, métodos e propondo a Abordagem Crítico Superadora para o ensino da Ginástica nas escolas e na formação de professores. Consideramos, ainda, a tese de Paraiso (2015) que apresentou os desafios de grupos de pesquisa para defender a Ginástica em bases materialista histórica dialética; e a tese de Lorenzini (2013) que estudou uma proposição de organizar os conteúdos clássicos da Ginástica no currículo escolar visando elevar a capacidade teórica dos estudantes.

\section{APONTAMENTOS DA PEDAGOGIA HISTÓRICO-CRÍTICA PARA O TRABALHO PEDAGÓGICO}

A natureza e especificidade do trabalho educativo está interrelacionada com modo de produção de vida das sociedades. Nesse sentido, a compreensão da categoria trabalho é central para o entendimento das particularidades do trabalho educativo. Sobre o trabalho, vale destacar, segundo Marx e Engels (2007, p. 32-33), que "[...] devemos começar por constatar o primeiro pressuposto de toda a existência humana e, também, de toda a história, a saber, o pressuposto de que os homens tem de estar em condições de viver para poder "fazer história". Os seres humanos precisam estar vivos e, portanto, necessitam produzir e reproduzir seus meios de existência. Por não encontrar imediatamente aquilo que precisam para estarem vivos na natureza, eles (os seres humanos) necessitam transformá-la. Neste processo, ao transformar a natureza, ao mesmo tempo, os seres humanos transformam a si mesmos fazendo com que saltos quantitativos e qualitativos no seu próprio desenvolvimento ocorram. Essa é a natureza ontológica do trabalho em geral.

Segundo Saviani (2013, p. 12-15), para reconhecera natureza ea especificidade da educação, toma como base a categoria trabalho. Ele advoga que o trabalho se instaura quando o homem transforma a natureza, antecipando mentalmente a sua ação, para produzir a sua existência. A esse processo é categorizado como trabalho material. Mas, no entanto, os seres humanos precisam se apropriar do conhecimento das propriedades do mundo real (ciência), de valorização (ética) e de simbolização (arte), sendo que isso é condição e consequência para produzir materialmente. A esse aspecto do trabalho Saviani confere a categoria de trabalho não-material.

É, pois, aí que reside a especificidade da educação escolar, ou seja, é para transmitir ideias, conceitos, atitudes, habilidades, hábitos, símbolos, valores, que foram construídos sócio e historicamente pela humanidade, que o professor atua em sala de aula. Nessa perspectiva, o trabalho educativo é entendido como a "organização dos meios (conteúdos, espaços, tempo e procedimentos) através dos quais, progressivamente, cada indivíduo singular realize, na forma de segunda natureza, a humanidade produzida historicamente". (SAVIANI, 2013, p. 13) 
Quanto a Educação Escolar e seus objetivos ressaltamos que devem estar voltados para ampliar, do nascimento a educação básica, as ações educativas que paulatinamente expandam os conteúdos de formação teórica/prático. Para exemplificar, expomos a seguinte representação gráfica:

Figura 1 - Conteúdos de Formação Operacional/Teórico

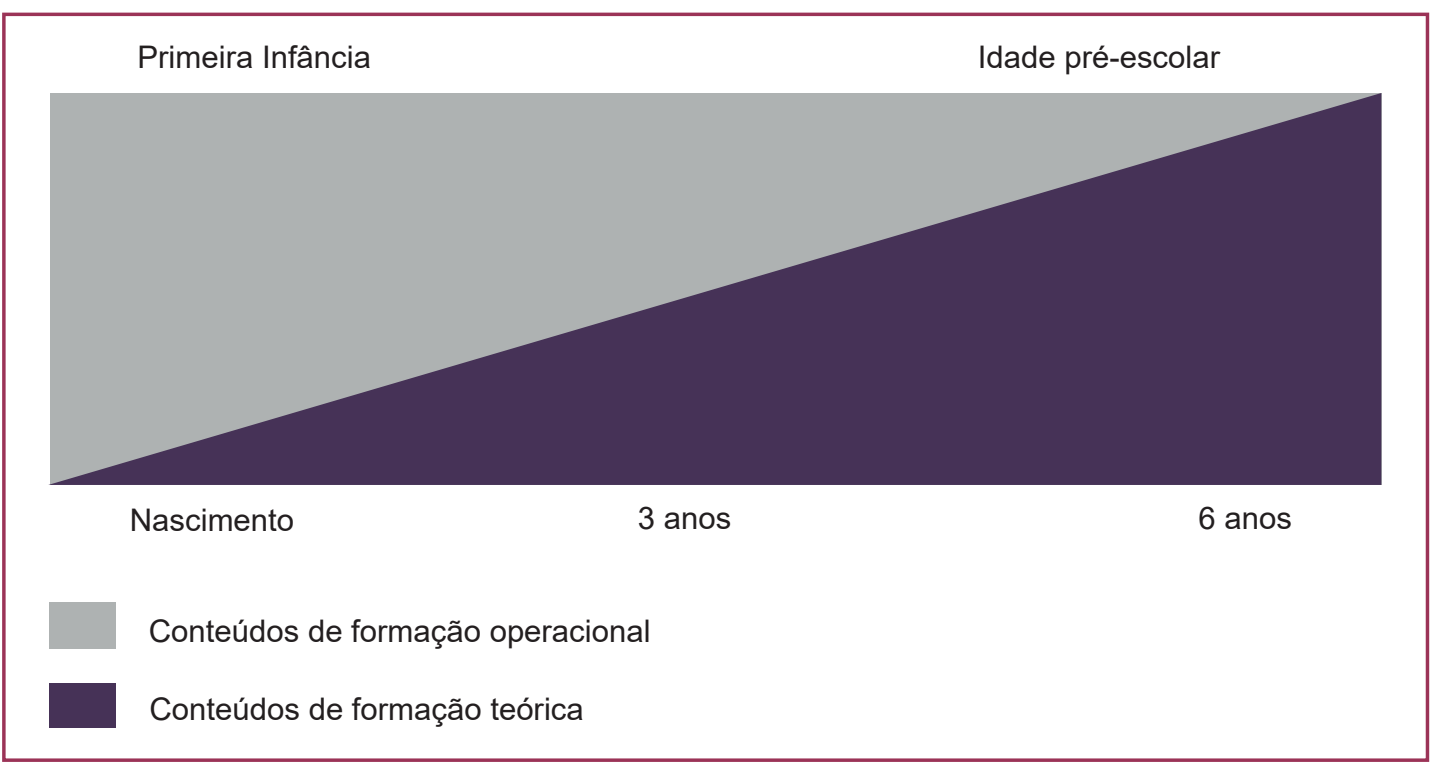

Fonte: MARTINS, 2012, p. 98 In: TEIXEIRA, 2018.

Aqui está localizado um dos grandes desafios aos docentes, em especial de Educação Física: pensar como selecionar e organizar os conteúdos da ginástica numa unidade de ensino. Esta preocupação, no caso da Educação Física Escolar, se dá no intuito de evitar a renúncia da ação pedagógica intencional nas aulas de Educação Física para desenvolver os conteúdos de formação teórica nos estudantes. Nesse sentido, a interrelação entre os conteúdos de formação operacional e os conteúdos de formação teórica é fundamental para potencializar o desenvolvimento das funções psicológicas dos aprendizes.

Sendo assim, os conteúdos de formação operacional dizem respeito as possibilidades de conhecimentos interdisciplinares que os professores se valem para fazer a sua intervenção pedagógica. Embora os conhecimentos de formação operacional não sejam transmitidos conceitualmente aos aprendizes na sala de aula, esses conteúdos pedagógicos, psicológicos, políticos, etc. auxiliam o professor na condução da sua pratica pedagógica na medida em que qualifica a intervenção e interferem, assim, no desenvolvimento do estudante, pois "Tais conhecimentos, presentes nas ações pedagógicas conduzidas pelo docente, mobilizam na criança os processos psicofísicos naturais, elementares, tendo em vista sua complexificação expressa em processos culturalmente instituídos, superiores." (MARTINS, 2015, p. 18) Já os conteúdos de formação teórica correspondem aos conceitos historicamente sistematizados que são transmitidos para os estudantes e que operam indiretamente no desenvolvimento das funções psicológicas do aprendiz, garantindo assim a formação de conceitos que corroboram para a possibilidade de formação fidedigna da imagem subjetiva da realidade objetiva. 
Para exemplificar, vamos tomar um conteúdo clássico da Ginástica que são os saltos. O conteúdo operacional do primeiro ciclo diz respeito ao conteúdo que implica o reconhecimento de si mesmo e suas próprias possibilidades de ação. No segundo ciclo, a apropriação de saltos cujo conteúdo implica no desenvolvimento da capacidade de saltar, com técnica, implica no domínio de conteúdos de formação teórica, sem o que o estudante não consegue organizar técnica e taticamente o seu saltar. A medida do avanço nos ciclos, isto vai implicando no domínio do conhecimento sistematizado e aprofundando técnicas e táticas que propiciem conteúdos e práticas organizadas conjuntamente escola/comunidade ou para muito além delas.

Ademais, estas múltiplas possibilidades de trato do conteúdo operacional e conteúdo teórico dizem respeito ao desenvolvimento da consciência pela mediação conteúdo-forma-destinatário. Isto significa que, ao planejar os conteúdos da Educação Física Escolar, não é possível fragmentar, cindir, desconsiderar a tríade conteúdoforma-destinatário.

O esquema a seguir desenvolvido por Martins (2015) e exposto em curso de formação continuada de professores das escolas do campo na Bahia, no período entre 2014 e 2019, nos permite explicar quea passagem da síncrese, da pseudoconcreticidade, para a síntese real do concreto, o concreto no pensamento, a abstração, implica um processo da passagem de conceitos espontâneos para conceitos científicos. E, este processo passa pela superação dos complexos associativos, coleção, cadeia, difuso e pseudoconceitos para a formulação de conceitos correspondentes ao real concreto no pensamento. A superação destes complexos, que são graus de sistematização do conhecimento do real concreto, se dá pela apropriação do conteúdo teórico e pelo trabalho educativo, sistemático, dos professores.

Figura 2 - Passagem de Conceitos Espontâneos para Conceitos Científicos

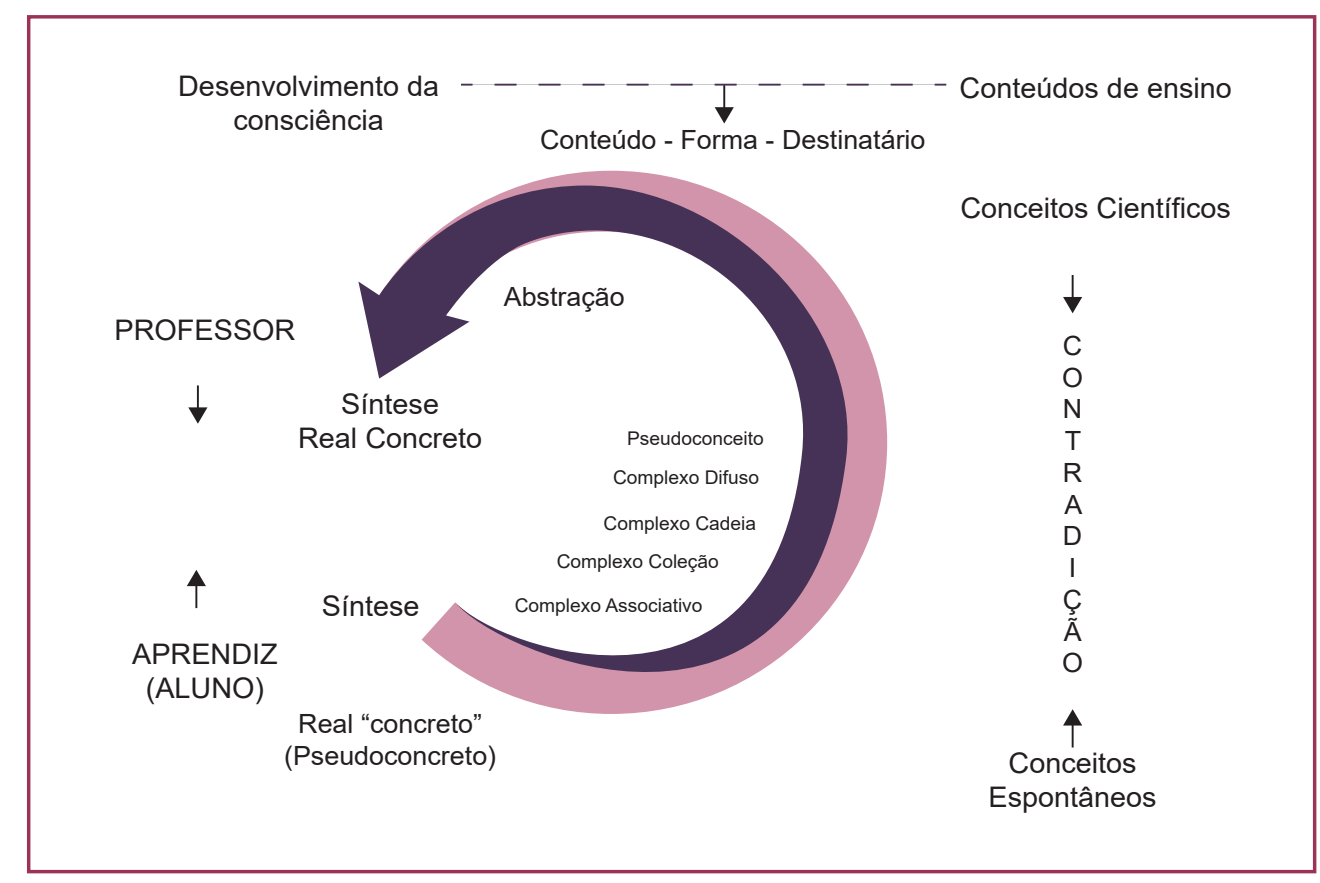

Fonte: MARTINS, Ligia. Exposição durante Curso de Formação Continuada de Professores para as Escolas do Campo, Ação Escola da Terra/PRONACAMPO/FACED/UFBA SEC.EDU/BA, MEC/SECADI/FNDE, 2015. 
A imagem acima representa, justamente, a relação indissociavelmente existente entre o trabalho educativo do professor e o processo de formação de conceitos no aprendiz. Nesse sentido, é fundamental para o professor entender o movimento do pensamento no processo de formulação dos conceitos científicos, pois são estes que permitem a apreensão do real concreto com maior fidedignidade. Ademais, as estruturas de generalização do pensamento pseudoconcreto, perpassando pelo pensamento por complexos, chegando até o pensamento abstrato são, embora interligadas, bastante particulares. Isto significa que sem atividades principais que incidam nas funções psicológicas superiores dos seres humanos - processos funcionais sensação, percepção, atenção, memória, linguagem, pensamento, imaginação, emoção, sentimento-, temos poucas possibilidades de desenvolver a consciência, a capacidade teórica, o reflexo do real concreto como concreto no pensamento.

Nesse sentido, as especificidades do pensamento pseudoconcreto apontam, segundo Martins (2016, p. 1551), a predominância da indefinição do significado da palavra, ou seja, a relação entre pensamento e a realidade é baseada em conceitos falsos que não conferem com o fato percebido sensorialmente pela criança. Assim, não há mediação de conceitos na relação da criança com o mundo, daí o motivo da identidade entre pensamento e ação ser elemento predominante nessa fase. Dessa maneira:

[...] na ausência de conhecimentos reais acerca dos vínculos que balizam as relações entre os objetos, a criança estabelece conexões subjetivas, fortuitas e carentes de qualquer ordenação lógica. Sob tais condições é que o pensamento infantil, nessa fase, resulta "sincrético" - combinando elementos que não mantêm entre si nenhuma correspondência objetiva. (MARTINS, 2016, p. 1551)

A fase de pensamento por complexos, que compreende temporalmente o término da infância e o início da adolescência, é marcada por diversas variações funcionais e estruturais. Não obstante, durante essa fase o pensamento do aprendiz busca estabelecer relações entre objetos distintos, de maneira ordenada, mas, no entanto, baseado predominantemente na sua própria experiência individual empírica. Nesse sentido, Martins (2016) discorre sobre a características do pensamento nessa fase, segunda ela:

O pensamento por complexos adquire um grau superior de coerência e objetividade. O sincretismo e a prevalência das conexões subjetivas próprias ao pensamento por agrupamentos começam a ceder lugar a vínculos reais estabelecidos entre as coisas por meio da experiência imediata. Os complexos abarcam, então, a união, ou generalização, de objetos diferentes, baseando-se em uma multiplicidade de vínculos entre eles, refletindo conexões práticas e casuais. (MARTINS, 2016, p. 1582)

Diferentemente do pensamento sincrético - o qual não há um estabelecimento concreto da palavra com a realidade - no pensamento por complexos, geralmente, o aprendiz já é capaz de estabelecer relações entre distintos elementos em busca de produzir generalizações, porém, ainda baseado em sua experiência empírica pessoal. Destarte, há cinco etapas que correspondem as formas distintas de desenvolvimento do pensamento por complexos cujas características possuem particularidades, a 
saber: complexo associativo, por coleção, por cadeia, complexos difusos e pseudoconceitos.

Em síntese, a forma como o aprendiz desenvolve a sua capacidade teórica, saindo de uma condição elementar em relação ao conteúdo estudado e chegando em um patamar superior de compreensão do objeto, a partir da formação de conceitos científicos, é o que está posto no esquema. Assim, o aprendizado do estudante, que por sua vez apresenta uma visão caótica, sincrética, baseada em pensamentos por complexos e pseudoconceitos, é elevada para uma visão sintética a partir da assimilação de conceitos científicos, mediante a intervenção do professor no processo pedagógico. Desta forma, o aprendiz, de posse dos conceitos científico, compreenderá a realidade de maneira fidedigna, considerando as relações e nexos existentes entre aquilo que se está estudando em particular (no caso a Ginástica) e as determinações do modo de produção capitalista que se expressam neste elemento da cultura corporal.

De acordo com Langlade e Langlade (1970), para o estudo dos problemas da ginástica é preciso compreender três aspectos:

a) a teoria geral;

b) a teoria especial (linhas, correntes ou modalidades);

c) sua didática.

O conhecimento dos problemas gerais, reconhecendo o passado e suas determinações no presente, são, por sua vez, essenciais para se compreender qualquer proposição atual. Nesse sentido, Langlade e Langlade (1970, p. 12) defendem que o conhecimento da Teoria Geral, especial e a didática do ensino da Ginástica devem estar pautado pelos seguintes objetivos diretos:

a) conhecimento histórico, passado e presente, das escolas, sistemas, métodos ou linhas de trabalho que existiram e existem;

b) inter-relação doutrinária-técnico-pedagógica de cada uma delas e suas influências nacionais e internacionais - passado/presente;

c) atualização, frente a cada forma de trabalho, de sua contribuição para a saúde, a educação e a beleza do homem;

d) apresentação global e atualizada dos fatos ginásticos frente à nova sociedade;

e) afirmação do conceito de universalização dos problemas e soluções ginásticas;

f) avaliação das diferentes formas de encarar o movimento na ginástica de acordo com seus objetivos de trabalho;

g) síntese das bases e princípios fundamentais gerais, aplicáveis à toda interpretação ginástica;

h) "previsão" da evolução do movimento ginástico, desenvolvendo possibilidades de retificações.

Na próxima seção trataremos de evidenciar os apontamentos que dão suporte ao trabalho educativo do professor no trato com o conhecimento da ginástica, considerando a ACS da Educação Física. 


\section{APONTAMENTOS DA ABORDAGEM CRITICO-SUPERADORA PARA O TRATO COM O CONHECIMENTO DA GINÁSTICA}

A Abordagem Crítico-Superadora (ACS), em linhas gerais, trata a cultura corporal do ponto de vista histórico, vinculando a produção das práticas corporais aos interesses da classe trabalhadora. Essa metodologia fundamenta a organização do trabalho pedagógico considerando a necessidade de que a escola trate do conhecimento historicamente produzido e acumulado pela humanidade, visando à elevação do pensamento teórico dos trabalhadores, fato esse que se conecta também com os anseios da teoria pedagógica histórico-crítica.

Para Soares e colaboradores (2012), a Educação Física é uma prática pedagógica que, no âmbito escolar, tematiza formas de práticas corporais como jogo, luta, dança, esporte e ginástica e tem por finalidade contribuir para a construção da visão de totalidade do aluno. Então, na medida em que o aluno, a partir das contribuições das diferentes ciências, consegue elaborar sínteses para explicar o real, a visão de totalidade é construída e as referências do pensamento são ampliadas. Isso permite um alcance maior na capacidade de explicar e de agir na realidade.

Porsua vez, a cultura corporal-jogo, dança, luta, esporte, ginástica-é uma parte da cultura humana. De acordo com Soares, et. al., (2012), ela é construída socialmente e é historicamente determinada, a partir de múltiplas relações estabelecidas pelos homens entre si e com a natureza, considerando experiências ideológicas, políticas, sociais e os sentidos estéticos, lúdicos, competitivos, agnósticos e outros.

Já a ginástica, dentro desta perspectiva, é entendida como "uma forma particular de exercitação onde, com ou sem uso de aparelhos, se abre a possibilidade de atividades que provocam valiosas experiências corporais, enriquecedoras da cultura corporal das crianças, em particular, e do homem, em geral". (SOARES et al., 2012, p. 76)

Ponderando isto, segundo Lorenzini (2013), o problema fundamental que a ginástica coloca aos estudantes consiste em desafiar as próprias possibilidades de exercitação tendo em vista a elaboração do pensamento teórico. Portanto, a ginástica contribui de forma efetiva com o desenvolvimento quando provoca a reflexão pedagógica e elevação da capacidade teórica dos estudantes.

Desta forma, o processo de elaboração de conceitos científicos acerca da ginástica parte de dados sincréticos passando à formação de representações e, desta, para dados mais elaborados iniciando a formação de generalizações conceituais, passando a sistematizá-las e finalmente à formação de conceitos abstratos identificando regularidades do objeto. Segundo Lorenzini e Taffarel (2018, p. 307) "a ginástica trabalhada na perspectiva da Educação Física Crítico-Superadora potencializou a elevação do pensamento teórico".

Nesse sentido, Teixeira (2018), baseando-se na perspectiva CríticoSuperadora, nos indica que não é suficiente apenas conhecer as operações das atividades de ginástica. $O$ ensino da ginástica na escola requer, também, que os estudantes apreendam as relações que determinam a existência da Ginástica, sua estrutura e desenvolvimento ao longo do processo histórico da humanidade, por ser esses elementos imprescindíveis para a reprodução social do conhecimento e produção de novas formas de reprodução da Ginástica. 
Inferimos, a partir dos estudos recentes (TEIXEIRA, 2018; PARAISO, 2015; LORENZINI, 2013) e de clássicos da metodologia do ensino da Educação Física (SOARES et al., 1992) e da ginástica (LANGLADE; LANGLADE) de que o trabalho pedagógico com a Educação Física nas escolas deve partir de uma concepção de formação que possibilite ao estudante constatar, interpretar, compreender, analisar e explicar a realidade social concreta, considerando a Cultura Corporal enquanto objeto da Educação Física e especificamente, no nosso caso em particular, o conteúdo da ginástica no contexto da educação do campo.

\subsection{O TRATO COM O CONHECIMENTO DA GINÁSTICA NAS ESCOLAS DO CAMPO}

A legitimação do conhecimento da ginástica nos programas de ensino, como adverte Soares et al. (2012, p. 76), Teixeira (2018), Paraiso (2015), Lorenzini (2013) e Almeida (2005) acontece na medida em que o referido conteúdo esteja presente nas escolas, em especial nas classes multisseriadas, e possibilite ao estudante a representação subjetiva da imagem objetiva das atividades ginásticas, por meio de um espaço livre para que possa vivenciar as suas próprias ações corporais e, com o domínio de conhecimentos clássicos, ir avançando nas elaborações teóricas e elevando assim o seu próprio padrão cultural.

Tendo em vista o encaminhamento de exemplo de elementos de uma proposta pedagógica, destacamos os estudos de Teixeira (2017, p. 146-147) que apresenta uma possibilidade de planejamento dos conteúdos da ginástica. Vamos emprega-los em um exemplo para a escola multisseriada no campo. Nesse sentido, podemos propor enquanto possibilidade para organizar os conteúdos selecionados em seus diferentes níveis:

Quadro 1 - Planejamento dos Conteúdos da Ginástica

\begin{tabular}{|c|c|c|c|}
\hline CONTEÚDOS & NÍVEL INICIAL & NÍVEL INTERMEDIÁRIO & NÍVEL AVANÇADO \\
\hline $\begin{array}{l}\text { Funções } \\
\text { diretas dos } \\
\text { aparelhos e } \\
\text { objetos da } \\
\text { Ginástica }\end{array}$ & $\begin{array}{c}\text { Apropriação das funções } \\
\text { diretas dos aparelhos e } \\
\text { objetos da Ginástica }\end{array}$ & $\begin{array}{l}\text { Realização de ações } \\
\text { estranhas as funções } \\
\text { diretas dos objetos e } \\
\text { aparelhos da ginástica, } \\
\text { motivadas principalmente } \\
\text { pelo uso em jogos } \\
\text { protagonizados }\end{array}$ & $\begin{array}{l}\text { Iniciação a realizar ações } \\
\text { da ginástica com o uso } \\
\text { dos objetos e aparelhos } \\
\text { a partir das funções } \\
\text { estabelecidas nas } \\
\text { respectivas modalidades } \\
\text { ginásticas }\end{array}$ \\
\hline $\begin{array}{c}\text { Bases e } \\
\text { fundamentos } \\
\text { da Ginástica }\end{array}$ & $\begin{array}{l}\text { Realização de ações } \\
\text { de diferentes apoios } \\
\text { e giros. Iniciação } \\
\text { aos fundamentos da } \\
\text { ginástica. }\end{array}$ & $\begin{array}{c}\text { Domínio das principais } \\
\text { formas de apoios e giros. } \\
\text { Realização e nomeação } \\
\text { dos fundamentos da } \\
\text { ginástica em situações } \\
\text { de jogo }\end{array}$ & $\begin{array}{l}\text { Domínio elementar } \\
\text { dos fundamentos da } \\
\text { ginástica. Inicio da } \\
\text { conceituação dos } \\
\text { fundamentos da ginástica }\end{array}$ \\
\hline $\begin{array}{l}\text { Posturas } \\
\text { básicas da } \\
\text { Ginástica }\end{array}$ & $\begin{array}{l}\text { Apropriação do } \\
\text { conhecimento do corpo } \\
\text { e suas possibilidades; } \\
\text { apropriação elementar } \\
\text { das posturas mais } \\
\text { simples da ginástica }\end{array}$ & $\begin{array}{c}\text { Apropriação das } \\
\text { principais formas } \\
\text { de ginástica e sua } \\
\text { nomeação }\end{array}$ & $\begin{array}{c}\text { Apropriação das posturas } \\
\text { básicas e sua realização } \\
\text { numa situação de } \\
\text { apresentação }\end{array}$ \\
\hline
\end{tabular}


Continuação do quadro 1.

\begin{tabular}{|c|c|c|c|}
\hline $\begin{array}{c}\text { História da } \\
\text { Ginástica }\end{array}$ & $\begin{array}{c}\text { Apropriação elementar } \\
\text { do conceito de Ginástica, } \\
\text { domínio dos nomes das } \\
\text { ações elementares e } \\
\text { objetos da Ginástica }\end{array}$ & $\begin{array}{c}\text { Apropriação elementar } \\
\text { das informações básicas } \\
\text { da origem da Ginástica }\end{array}$ & $\begin{array}{c}\text { Assimilação das } \\
\text { principais formas de } \\
\text { ginástica, e iniciação aos } \\
\text { conhecimentos primários } \\
\text { de sua historia }\end{array}$ \\
\hline $\begin{array}{c}\text { Réries } \\
\text { ginásticas }\end{array}$ & $\begin{array}{c}\text { curtas elaboradas pelo de series } \\
\text { adulto, seguindo a } \\
\text { imitação do professor, } \\
\text { com o uso limitado de } \\
\text { objetos }\end{array}$ & $\begin{array}{c}\text { Realização de series } \\
\text { curta elaboradas pelo } \\
\text { adulto, em a necessidade } \\
\text { da presença do } \\
\text { professor, com maior } \\
\text { liberdade no uso dos } \\
\text { objetos }\end{array}$ & $\begin{array}{c}\text { Realização de series } \\
\text { mais longa elaborada } \\
\text { pelo adulto com a } \\
\text { participação das } \\
\text { crianças, com ampla } \\
\text { liberdade no uso dos } \\
\text { objetos e aparelhos }\end{array}$ \\
\hline $\begin{array}{c}\text { Diferentes } \\
\text { formas de } \\
\text { Ginástica }\end{array}$ & $\begin{array}{c}\text { Apropriação e } \\
\text { classificação dos objetos, } \\
\text { aparelhos, ações de } \\
\text { algumas modalidades da } \\
\text { ginástica - duas }\end{array}$ & $\begin{array}{c}\text { Apropriação e } \\
\text { classificação dos objetos, } \\
\text { aparelhos, ações de } \\
\text { algumas modalidades da } \\
\text { ginástica - três a quatro }\end{array}$ & $\begin{array}{c}\text { Identificação das } \\
\text { diferenças básicas em } \\
\text { relação as modalidades } \\
\text { conhecidas }\end{array}$ \\
\hline
\end{tabular}

Fonte: Teixeira (2018, p 144 - 145).

No quadro anterior, vamos encontrar uma proposição de conteúdo a serem levados em consideração no planejamento vertical e horizontal, com conhecimentos clássicos da ginástica a serem tratados nas escolas do campo, em classes multisseriadas. Teixeira (2018) destaca a relevância do ensino da ginástica, desde os primeiros anos de escolarização até a vida adulta, uma vez que os referidos conhecimentos servem de base para a maioria das atividades da cultura corporal.

\section{CONSIDERAÇÕES FINAIS}

Ao longo do texto, defendemos três pontos que se inter-relacionam e constituem elementos sobre a teoria pedagógica histórico-crítica, sobre a abordagem teórico-metodológica do ensino da Educação Física e, em especial, sobre a teoria da ginástica. Ambas as proposições teóricas contribuem na perspectiva defendida por Saviani (2013) e por Caldart (2020) em relação a função social da escola, em especial das Escolas do Campo, a saber: (1) não nascemos seres humanos, mas nos tornamos a medida em que realizamos, em cada um de nós, a humanidade que se constitui em relações sociais de produção da vida, processo este que exige a apropriação da cultura elaborada, sendo a escola na atualidade o locuns principal para apropriação da cultura e elevação da capacidade teórica dos estudantes para compreender e transformar a realidade social; (2) que a Educação Física, que tem como objeto de estudo a cultura corporal, se justifica no currículo escolar à medida que contribui juntamente com os demais componentes curriculares para elevar a capacidade teórica dos estudantes; contribui para elevar o padrão cultural e isto exige a consideração de princípios para tratar o conhecimento no currículo, considerando a contemporaneidade e relevância social da escola; (3) que a ginástica, enquanto conteúdo clássico, historicamente produzido e socialmente apropriado, com seus fundamentos e suas bases - saltar, rolar, embalar, balançar, girar -, deve ser tratado desde a educação infantil até a educação de jovens e adultos, levando em consideração a tríade conteúdo-forma e destinatário, no planejamento vertical e 
horizontal, permitindo-se assim que, ao se apropriar deste conteúdo na escola, os estudantes elevem sua capacidade teórica para constatar, compreender, explicar e agir no mundo construindo a cultura corporal na perspectiva da emancipação da classe trabalhadora da cidade e do campo.

Nesse sentido, o trato com o conhecimento da ginástica em classes multisseriadas poderá se organizar a partir do plano vertical e horizontal, considerando os ciclos de ensino enquanto proposta para superação da seriação que não atende com qualidade as necessidades de organização do trabalho pedagógico do professor nas classes regulares em geral e, principalmente, nas classes multisseriadas, sempre considerando a indissociabilidade entre conteúdo-forma e destinatário.

Sendo assim, considerando a Abordagem Crítico-Superadora, estudar a Ginástica na educação básica requer a apreensão desse conteúdo considerando a sua gênese, sua estrutura e seus fundamentos, tendo em vista a aplicação crítica e concreta na vida dos sujeitos do campo, levando em conta as condições da comunidade. Assim, a Ginástica é um conteúdo clássico da cultura corporal sem o qual a compreensão da totalidade da realidade concreta fica limitada. Nesse sentido, é fundamental a garantia da transmissão do referido conhecimento para que as escolas públicas do campo não deixem de cumprir a sua função social.

Apresentamos, por fim, um rol de conteúdos constituídos por conceitos básicos que necessitam ser desenvolvidos inclusive nas aulas de Ginástica, em classes multisseriadas. Estes conteúdos que compõe a cultura corporal constituem as bases e fundamentos da Ginástica que precisam ser garantidos a todos os estudantes em seu processo de escolarização. Para isso, as escolas precisam permanecer abertas, com estrutura e infraestrutura necessária para garantir as condições necessárias para o trabalho pedagógico do professor e, assim, a elevação da capacidade teórica dos estudantes do campo e a superação de limites que estão postos para a práxis pedagógica em classes multisseriadas, tendo em vista um ensino que vise formar indivíduos capazes de compreender para transformar a realidade social vigente e fundamentalmente, com professores valorizados no exercício de sua profissão.

\section{REFERÊNCIAS}

ALMEIDA, Roseane Soares. A ginástica na escola e na formação de professores. 2005. 157 f. 2005. Tese (Doutorado em Educação) - Faculdade de Educação, Universidade Federal da Bahia, Salvador. 2005.

BRASIL. Lei $n^{\circ}$. 9.394. Diretrizes e bases da educação nacional, de 20 de dezembro de 1996. Brasília: Diário Oficial da União, Brasília, DF, ano 138, n. 248, 23 dez.1996.

BRASIL. Ministério da Educação. Diretrizes operacionais para a educação básica nas escolas do campo. Brasília: SECAD/MEC, 2002.

BRASIL. Ministério da Educação. Secretaria de Educação Continuada, Alfabetização e Diversidade. Projeto Base. Brasília: SECAD/MEC, 2008. 
BRASIL. Ministério da Educação. Secretaria de Educação Continuada, Alfabetização e Diversidade. Programa Escola Ativa. Orientações pedagógicas para a formação de educadoras e educadores. Brasília: SECAD/MEC, 2009.

BRASIL. II PNERA. Relatório da II Pesquisa nacional sobre educação na reforma agrária. Brasília: Ministério do Desenvolvimento Agrário, 2015. Disponível em: https://www. ipea.gov.br/portal/images/stories/PDFs/relatoriopesquisa/150618 relatorio ii pesquisa $\% 20$ nacional.pdf. Acesso: 05 maio 2020.

INEP. Censo escolar de 2019. Brasília: Ministério da Educação, 2019.

LANGLADE, Alberto; LANGLADE, Nelly R. Teoria general de la gimnasia. Buenos Aires: Stadium, 1970.

LORENZINI Ana Rita. Conteúdo e método da educação física escolar: contribuições da Pedagogia Histórico-Crítica e da Metodologia Crítico-Superadora no trato com a ginástica. Salvador. Tese [Doutorado em Educação] - Faculdade de Educação, Universidade Federal da Bahia, 2013.

LORENZINI, Ana; TAFFAREL, Celi. Os níveis de sistematização da ginástica para formação de conceitos na educação escolar. Revista Brasileira de Ciências do Esporte, v. 40, n. 3, p. 302-308, 2018.

MARSIGLIA, Ana; MARTINS, Lígia. Contribuições gerais para o trabalho pedagógico em salas multisseriadas. Nuances: Estudos sobre educação, v. 25, n.1, p. 176-192, jan./abr. 2014.

MARSIGLIA, Ana; MARTINS, Lígia. As perspectivas construtivista e histórico-crítica sobre o desenvolvimento da escrita. Campinas, SP: Autores Associados, 2015.

MARTINS, Lígia M. Material didático da Formação Escola da Terra. Salvador: UFBA, 2015.

MARTINS, Lígia. O desenvolvimento do psiquismo e a educação escolar: contribuição à luz da psicologia histórico-cultural e da pedagogia histórico crítica. Campinas, SP: Autores Associados, 2013.

MARTINS, Lígia. Desenvolvimento do pensamento e educação escolar: etapas de formação de conceitos à luz de Leontiev e Vigotski. Fórum linguístico, v.13, n.4, p. 1572-1586, out./ dez. 2016.

MARTINS, Lígia Márcia; ABRANTES, Angelo Antonio; FACCI, Marilda Gonçalves Dias. (org.). Periodização Histórico-Cultural do Desenvolvimento Psíquico: do nascimento à velhice. Campinas, SP: Autores Associados, 2017.

MARX, Karl; ENGELS, Friedrich. A Ideologia alemã. São Paulo: Boitempo, 2007.

MONTORO, X. A. Capitalismo y Economía Mundial: bases teóricas y análisis empírico para la comprensión de los problemas económicos del siglo XXI. Madrid: Instituto Marxista de Economía, 2014.

PARAISO, Cristina. 0 trato com o conhecimento da ginástica na escola: contribuições para uma proposta pedagógica pautada na abordagem crítico- superadora da educação física. 2015. Tese (Doutorado em Educação) - Universidade Federal da Bahia, Faculdade de Educação, Salvador, 2015.

SAVIANI, Dermeval. Escola e Democracia. 42. ed. Campinas, SP: Autores Associados, 2012. 
SAVIANI, Dermeval. Pedagogia Histórico-Crítica: primeiras aproximações. 11. ed. Campinas, SP: Autores Associados, 2013.

SOARES, Carmem L. et al. Metodologia de Ensino de Educação Física. 2. ed. São Paulo: Cortez, 2012.

TEIXEIRA, Davi Romão. Educação física na pré-escola: contribuições da metodologia do ensino crítico-superadora. 2018. Tese (Doutorado em Educação) - Faculdade de Educação, Universidade Federal da Bahia, 2018.

\section{Apoio:}

O presente trabalho foi realizado com apoio da Coordenação de Aperfeiçoamento de Pessoal de Nível Superior -Brasil (CAPES) - Código de Financiamento 001. This study was financed in part by the Coordenação de Aperfeiçoamento de Pessoal de Nível Superior - Brasil (CAPES) - Finance Code 001. 